\title{
The epidemiology of back pain and its relationship with depression, psychosis, anxiety, sleep disturbances, and stress sensitivity: Data from 43 low- and middle-income countries
}

Brendon Stubbs*1,2, Ai Koyanagi ${ }^{3,4}$, Trevor Thompson ${ }^{5}$, Nicola Veronese ${ }^{6,7}$, Andre F. Carvahlo $^{8}$, Marco Solomi ${ }^{7,9}$, James Mugisha ${ }^{10,11}$, Patricia Schofield ${ }^{12}$, Theodore Cosco ${ }^{13}$, Nicky Wilson $^{14}$, Davy Vancampfort ${ }^{15,16}$

1. Physiotherapy Department, South London and Maudsley NHS Foundation Trust, Denmark Hill, London SE5 8AZ, United Kingdom

2. Health Service and Population Research Department, Institute of Psychiatry, Psychology and Neuroscience, King's College London, De Crespigny Park, London, Box SE5 8AF, United Kingdom

3. Research and Development Unit, Parc Sanitari Sant Joan de Déu, Universitat de Barcelona, Fundació Sant Joan de Déu, Dr. Antoni Pujadas, 42, Sant Boi de Llobregat, Barcelona 08830, Spain

4. Instituto de Salud Carlos III, Centro de Investigación Biomédica en Red de Salud Mental, CIBERSAM, Monforte de Lemos 3-5 Pabellón 11, Madrid 28029, Spain

5. Faculty of Education and Health, University of Greenwich, London, United Kingdom

6. Geriatrics Division, Department of Medicine-DIMED, University of Padova, Italy

7. Institute of Clinical Research and Education in Medicine (IREM), Padova, Italy

8. Translational Psychiatry Research Group and Department of Clinical Medicine, Faculty of Medicine, Federal University of Ceara, Fortaleza, CE, Brazil

9. Department of Neurosciences, University of Padova, Padova, Italy

10. Kyambogo University, Kampala, Uganda

11. Butabika National Referral and Mental Health Hospital, Kampala, Uganda

12. Faculty of Health, Social Care and Education, Anglia Ruskin University, Chelmsford, United Kingdom

13. Centre for Global Mental Health, Health Service and Population Research Department, Institute of Psychiatry, King's College, De Crespigny Park, London, SE5 8AF, United Kingdom

14. Physiotherapy Department, Kings College London, Denmark Hill, United Kingdom

15. KU Leuven Department of Rehabilitation Sciences, Leuven, Belgium

16. KU Leuven, University Psychiatric Center KU Leuven, Leuven-Kortenberg, Belgium

* Corresponding author: Brendon Stubbs, Head, Physiotherapy Department, South London and Maudsley NHS Foundation Trust, Denmark Hill, London, United Kingdom. Tel: 0044 208 3003100, fax 00442032282702 email: brendon.stubbs@kcl.ac.uk 


\begin{abstract}
Background: Back pain (BP) is a leading cause of global disability. However, populationbased studies investigating its impact on mental health outcomes are lacking, particularly among low- and middle-income countries (LMICs). Thus, the primary aims of this study were to: (1) determine the epidemiology of BP in 43 LMICs; (2) explore the relationship between BP and mental health (depression spectrum, psychosis spectrum, anxiety, sleep disturbances and stress).
\end{abstract}

Methods: Data on 190,593 community-dwelling adults aged $\geq 18$ years from the World Health Survey (WHS) 2002-2004 were analyzed. The presence of past-12 month psychotic symptoms and depression was established using questions from the Composite International Diagnostic Interview. Anxiety, sleep problems, stress sensitivity, and any BP or chronic BP (CBP) during the previous 30 days were also self-reported. Multivariable logistic regres- sion analyses were undertaken.

Results: The overall prevalence of any BP and CBP were $35.1 \%$ and $6.9 \%$ respectively. Significant associations with any BP were observed for subsyndromal depression [OR (odds ratio $)=2.21$, brief depressive episode $(\mathrm{OR}=2.64)$, depressive episode $(\mathrm{OR}=2.88)$, psychosis diagnosis with symptoms $(\mathrm{OR}=2.05)$, anxiety $(\mathrm{OR}=2.12)$, sleep disturbance $(\mathrm{OR}$ $=2.37$ ) and the continuous variable of stress sensitivity. Associations were generally more pronounced for chronic BP.

Conclusion: Our data establish that BP is associated with elevated mental health comorbidity in LMICs. Integrated interventions that address back pain and metal health comorbidities might be an important next step to tackle this considerable burden.

Key words: Back pain, chronic back pain, mental health, mental illness, depression, psychosis, anxiety, sleep problems, stress sensitivity, low- and middle-income countries 


\section{Introduction}

Lower back pain (LBP) is a leading cause of global disability, with a global point prevalence of $9.4 \%$ (95\% CI $=9.0$ to $9.8 \%$ ) [1]. LBP ranked as the number one cause of disability among 291 conditions, and sixth in terms of overall burden in the Global Burden of Disease 2010 study [1, 2]. Among Western populations, a plethora of evidence has demonstrat- ed that back pain is associated with a range of deleterious consequences such as reduced quality of life, heightened risk of other physical health comorbidities and greatly increased health care costs [3-6]. Given the rising prominence of the biopsychosocial model, a number of studies, largely focused on Western populations, have highlighted the important role of poor mental health as a risk factor for LBP [7] and as a conse- quence of a LBP episode [8].

To date, only a few large representative multinational studies have considered the mental health status of people with back pain, with a no- table paucity in low- and middle-income countries (LMICs). However, there are indications that back pain is also highly prevalent in LMICs [9], where it is a source of substantial economic and health burden [10]. Previously, one large-scale multinational study [11] using data from the World Mental Health Survey including 5 LMICs (Ukraine, Mexico, Colombia, Nigeria, South Africa) found that the presence of chronic back/neck pain is associated with 2.3, 2.2, and 1.6 times greater odds for mood disorders, anxiety disorders and alcohol abuse respectively.

While progress has been made in attempting to understand the mental health impact of back pain, a number of pertinent questions re- main unanswered. First, while the relationship between back pain and mental health disorders (including depression, psychosis spectrum, anxiety and stress sensitivity) is equivocal, there are no studies explor- ing these associations thoroughly in LMICs. This is an important re- search gap given that the association between back pain and mental health symptoms or disorders in LMICs may differ from high-income settings, owing to factors such as suboptimal management of physical and mental health conditions with limited availability of non- pharmacologic or pharmacologic treatments $[12,13]$. Second, as people in LMICs mostly rely on labor-demanding jobs in the informal sector with no job security or compensation for lost income, maintaining good mental and physical health is crucial for their livelihoods. There- fore, there is a need to elucidate the potential mental health burden among people with back pain in LMICs.

Thus, the aims of the current study were to: (1) Determine the epidemiology of back pain (any back pain and chronic back pain) in 43 LMICs; and (2) explore the relationship between back pain and mental health (depression type, psychosis, anxiety, sleep problems, and stress sensitivity). Our hypothesis was that people with back pain would have worse mental health and this would be more pronounced among those with chronic back pain.

\section{Methods}

The World Health Survey (WHS) was a cross-sectional, community- based study undertaken in 2002-2004 in 70 countries worldwide. Single-stage random sampling and stratified multistage random cluster sampling were conducted in 10 and 60 countries respectively. Details of the survey have been provided elsewhere (http://www. who.int/healthinfo/survey/en/). Briefly, persons aged $\geq 18$ years with a valid home address were eligible to participate. Each member of the household had equal probability of being selected with the use of Kish tables. The data were collected in all countries using the same question- naire although some countries used a shorter version. The individual re- sponse rate (ratio of completed interviews among selected respondents after excluding ineligible respondents from the denominator) 
ranged from 63\% (Israel) to 99\% (Philippines) [14]. Ethical approval to conduct this survey was obtained from ethical boards at each study site. Sampling weights were generated to adjust for non-response and the population distribution reported by the United Nations Statistical Division. Informed consent was obtained from all participants.

Data from 69 countries were available. The data were nationally representative in all countries with the exception of China, Comoros, the Republic of Congo, Ivory Coast, India, and Russia. Countries without

any sampling information (10 countries - Austria, Belgium, Denmark, Germany, Greece, Guatemala, Italy, Netherlands, Slovenia, UK) were excluded. Furthermore, 10 high-income countries (Finland, France, Ireland, Israel, Luxembourg, Norway, Portugal, Sweden, Spain, United Arab Emirates) were excluded as the focus was specifically on LMICs. Of the remaining countries, we further omitted 6 countries (Congo, Mali, Mexico, Slovakia, Swaziland, Turkey) as over $25 \%$ of the data on any back pain and chronic back pain was missing. Thus, the final sample included 190,593 individuals from 43 countries, which corresponded to 19 low-income and 24 middle-income countries according to the World Bank classification at the time of the survey (2003). Furthermore, ac- cording to the United Nations' classification system (http://unstats.un. org/unsd/methods/m49/m49regin.htm), these countries corresponded to 17 countries in Africa $(n=71,346), 5$ in the Americas $(n=$ 23,986), 13 in Asia $(n=81,633)$, and 8 in Europe $(n=13,628)$.

\subsection{Variables}

\subsubsection{Back pain}

Participants were first asked "Have you experienced back pain (including disc problems) during the last 30 days?" with Y/N answer options. Those who answered affirmatively to this question were then asked "How many days did you have this back pain during the last 30 days?” We operationalized any back pain as those who answered 'yes' to the first question, and chronic back pain as those who claimed to have had back pain on all 30 days in the last 30 days.

\subsubsection{Mental health conditions}

\subsubsection{Depression type}

The severity of depressive symptoms was established based on the individual questions of the World Mental Health Survey version of the Mental Health Composite International Diagnostic Interview (CIDI), which assessed the duration and persistence of depressive symptoms in the past 12 months [15]. Following the algorithms used in a previous WHS publication [16], four mutually exclusive groups were established based on the ICD-10 Diagnostic Criteria for Research (ICD-10-DCR) where criterion B referred to symp- toms of depressed mood, loss of interest, and fatigability. The algorithms used to define the four groups were the following: (a) Depressive episode group: at least two criterion B symptoms together with a total of at least four depressive symptoms lasting two weeks most of the day or all of the day. (b) Brief depressive episode group: same criteria as depressive episode above but not meeting the two-week duration criterion. (c) Subsyndromal depression: at least one criterion B symptom together with the total number of symptoms being three or less. The criteria of duration of at least two weeks and the presence of symptoms during most of the day had to be met. (d) No depressive disorder group: none of the above. 


\subsubsection{Psychosis.}

Participants were asked whether they had ever been diagnosed of having schizophrenia or psychosis. All participants, re- gardless of a psychosis diagnosis, were asked questions on positive psy- chotic symptoms which came from the CIDI 3.0 [15]. This psychosis module has been reported to accord highly with clinician ratings [17]. The hallucinations question excluded conditions associated with sleep-related states or substance use. Specifically, respondents were asked the following questions with answer options 'yes' or 'no':

During the last 12 months, have you experienced: (a) 'A feeling something strange and unexplainable was going on that other people would find hard to believe?' (delusional mood). (b) 'A feeling that people were too interested in you or there was a plot to harm you?' (delusions of reference and persecution). (c) 'A feeling that your thoughts were being directly interfered or controlled by another person, or your mind was being taken over by strange forces?' (delusions of control). (d) 'An experience of seeing visions or hearing voices that others could not see or hear when you were not half asleep, dreaming

or under the influence of alcohol or drugs?' (hallucinations). Individuals who endorsed at least one of the four above-mentioned psychotic symptoms were considered to have psychotic symptoms. Based on information on psychosis diagnosis and psychotic symptoms, we created four mutually exclusive psychosis categories: (1) no symptoms and no diagnosis; (2) at least one symptom and no diagnosis; (3) a diagnosis and no symptoms; and (4) at least one symptom with a diagnosis $[18,19]$.

\subsubsection{Sleep problems}

Sleep problems were assessed by the question "Overall in the last 30 days, how much of a problem did you have with sleeping, such as falling asleep, waking up frequently during the night or waking up too early in the morning?” with answer options none, mild, moderate, severe and extreme. Those who answered severe and extreme were considered to have sleep problems. This definition has been used in previous publications using the same survey question on sleep problems [20-22].

\subsubsection{Anxiety}

Anxiety was assessed by the question "Overall in the past 30 days, how much of a problem did you have with worry or anxiety?” Respondents could answer: none, mild, moderate, severe or extreme. In the current study those who answered severe and extreme were categorized as having anxiety [22,23]. Data for this variable was missing from Morocco.

\subsubsection{Stress sensitivity.}

Stress sensitivity in the last month was assessed by two questions: "How often have you felt that you were unable to control the important things in your life?"; and "How often have you found that you could not cope with all the things that you had to do?” The answer options to these questions were: never ( core $=1$ ), almost never (score $=2$ ), sometimes (score $=3$ ), fairly often (score $=4$ ), very often (score $=5$ ). The scores of the two questions were added to create a scale ranging from 2 to 10 [24]. Brazil, Hungary, and Zimbabwe lacked information on stress sensitivity. 


\subsubsection{Control variables}

Variables on sex, age, highest education achieved (no formal educa- tion, primary education, secondary or high school completed, or tertiary education completed), wealth, setting (rural or urban), smoking, and al- cohol consumption were used as control variables. The selection of these variables was based on past literature [25]. Principal component analysis based on 15-20 assets was performed to establish country- wise wealth quintiles. The question on smoking was 'Do you currently smoke any tobacco products such as cigarettes, cigars, or pipes?' with the answer options being 'daily', 'yes, but not daily', or 'no, not at all'. This variable was dichotomized into those who smoked regardless of frequency (i.e. daily or not daily) (current smokers) and those who do not smoke. Alcohol consumption was assessed by first asking the question 'Have you ever consumed a drink that contains alcohol (such as beer, wine, etc.)?' Respondents who replied 'no' were considered lifetime abstainers. If the respondent replied affirmatively, then he/she was asked how many standard drinks of any alcoholic beverage he/ she had on each day of the past 7 days. The number of days in the past week in which 4 (female) or 5 (male) drinks were consumed was calculated, and a total of 12 and N3 days in the past 7 days were considered infrequent and frequent heavy drinking respectively. All other respondents, apart from lifetime abstainers, were considered nonheavy drinkers [22].

\subsection{Statistical analysis}

The statistical analysis was performed with Stata 14.1 (Stata Corp LP, College station, Texas). The age- and sex-adjusted prevalence of any back pain and chronic back pain for each country was estimated by using the United Nations population pyramids for the year 2010 (http://esa.un.org/wpp/Excel-Data/population.htm) as the standard

population. The difference in sample characteristics between those with and without any back pain or chronic back pain was tested by Chi-squared tests and Student's t-tests for categorical and continuous variables respectively.

Multivariable logistic regression analysis was done to assess the association between mental health conditions (exposure variables) and back pain or chronic back pain (outcome variables). The mental health conditions examined were depression type, psychosis, anxiety, sleep problems, and stress sensitivity. These variables were included separately in the models. The models were adjusted for age, sex, educa- tion, wealth, setting, smoking, alcohol consumption, and country. We repeated the analysis stratifying by region for all mental health condi- tions with the exception of psychosis to assess whether the associations observed are consistent across geographical locations. We were unable to conduct regionwise analyses for psychosis since the prevalence of some categories of this variable was extremely low [e.g. diagnosis and no symptoms $0.49 \%(n=863)$ ].

All variables were included in the models as categorical variables with the exception of age and stress sensitivity which were continuous variables. Adjustment for country was done by including dummy variables in the models, as in previous WHS publications [22,26]. Morocco was excluded from analyses on anxiety as it had no informa- tion on this variable.

Furthermore, this was also the case for Brazil, Hungary, and Zimbabwe for the variable on stress sensitivity. The sample weighting and the complex study design were taken into account in all analyses. Results from the logistic regression models are presented as odds ratios (ORs) with 95\% confidence intervals (CIs). The level of statistical significance was set at $\mathrm{p} b 0.05$. 


\section{Results}

The total sample included was 190,593 with the sample size of the countries ranging from 929 (Latvia) to 10,687 (India) (Table 1). The overall prevalence was 35.1\% for any back pain and $6.9 \%$ for chronic back pain. The age- and sex-adjusted prevalence range for any back pain was $13.7 \%$ (China) to $57.1 \%$ (Nepal), with more than half of the population also having back pain in Bangladesh (53.1\%) and Brazil (52.0\%). For chronic back pain, the lowest prevalence was observed in Myanmar (0.6\%), with the highest rates in Morocco (16.5\%) and Nepal (16.4\%) (Table 1, Fig. 1). The mean (SD) age of the sample was 38.4 (16.0) years and $50.7 \%$ of the sample consisted of females (Table 2). Older age, female sex, lower levels of education and wealth, urban setting, current smoking, alcohol consumption, depression, psychosis, anxiety, sleep problems, and higher levels of stress sensitivity were all significantly associated with any back pain or chronic back pain, although urban setting was significant only for any back pain.

\subsection{Relationship between back pain and mental health}

The prevalence of any back pain and chronic back pain by the 5 men- tal health conditions is illustrated in Fig. 2. Compared to those who do not have that mental health condition, the prevalence of any back pain or chronic back pain was much higher for those who have any depression or psychosis type, anxiety, and sleep problems. For the stress sensitivity score, there was a linear increase in the prevalence of both forms of back pain with higher severity of stress sensitivity. The associ- ation between mental health conditions and both forms of back pain es- timated by multivariable logistic regression is shown in Table 3 . In the overall sample, compared to those without the mental health condition, all types of mental ailments were associated with a significant N2 times higher odds for any back pain. For stress sensitivity, a one-unit increase in severity (range 2-10) was associated with 1.13 times higher odds for any back pain. Similar results were obtained for chronic back pain, with particularly high odds observed for depressive episode. The results of the region-wise analyses are presented in eTable 1 of the Webappendix. Results were similar across continents.

\section{Discussion}

\subsection{General findings}

This large-scale study including 190,593 participants from 43 LMICs demonstrates that the overall prevalence of any back pain and chronic back pain was $35.1 \%$ and $6.9 \%$ respectively. The current study is the largest of its kind and contains several novel results. Our data suggest that both any back pain and chronic back pain are associated with an increased risk of depression and psychosis spectrum, sleep disorders, anxiety and stress sensitivity.

Furthermore, these associations were similar across continents despite a large variation in the prevalence of back pain across regions.

The rate of chronic back pain at $6.9 \%$ in the current study is lower than the $18 \%$ (95\% CI = 14-24\%) observed in a recent meta-analysis [9], which included 79 surveys from general adult populations, elderly general populations and workers from 28 LMICs. A possible reason might be that higher LBP rates were observed in the studies focusing solely on elderly general population and workers while the current study did not target these subpopulations specifically. Next to this, in the current study, we applied more strict criteria for chronic back pain, i.e. chronic back pain was defined as having had back pain on all 30 days in the last 30 days. 
It is perhaps of little surprise that back pain is associated with de- pression, given the established bidirectional relationship in Western populations [7,8,27]. However, very few studies have considered the re- lationship between the depression spectrum (i.e. subsyndromal depres- sion and brief depressive episodes) and back pain. In fact, to the best of our knowledge, no representative multi-national study has considered this relationship between the depression spectrum and back pain. Our data clearly indicate that all types of depression are associated with in- creased odds of experiencing pain. Potential factors that may account for the high back pain and depression comorbidity cannot be deter- mined from the available data. One possible factor is the underlying shared pathophysiology, since both depression and pain facilitate mod- ulation in the periaqueductal gray, amygdala, and hypothalamus re- gions [28,29]. Second, both pain and depression are associated with and exacerbated by social isolation and reduced physical activity [30, 31]. In addition, genetics and in particular single nucleotide polymor- phism in the NTRK3 gene may account for the pain and depression rela- tionship [32]. Within the context of some LMICs, the high prevalence of HIV and tuberculosis [33] may also account for both the depression [34] and back pain [35] observed in the current study.

There is a paucity of studies investigating subclinical psychosis and back pain in the literature. Previously, one study among people in North-America found that psychotic experiences were significantly associated with an increased risk of chronic pain (OR 1.94) [36]. Another study found that psychotic-like experiences are associated with severe pain in LMICs [37]. However, no study has yet to our knowledge demon- strated the heightened relationship between back pain and sub-clinical psychosis found here. Our study also found that psychotic disorder (including schizophrenia) with symptoms was associated with 2.05 and 2.68 times higher odds for back pain and chronic back pain respec- tively. Understanding the relationship between back pain and psychosis is important since both conditions are associated with a lower quality of life [38]. Interestingly, while experimental pain research has demon- strated that pain sensitivity is reduced in people with schizophrenia in- cluding those who do not take medication [39], our results suggest this may not translate into lower pain prevalence in schizophrenia patients at the community level. The association between back pain and psy- chotic experiences may possibly be due to psychological distress arising from back pain [40].

Our data established that both back pain and chronic back pain were associated with approximately two-fold increase odds of anxiety. To our knowledge, the current data are the first to establish this relationship in a multinational LMIC group. There are a number of factors that could account for this relationship. First, experiencing pain, can stimulate feelings of anxiety, which can increase one's sensitivity to pain [41]. Moreover, both chronic pain and anxiety share common underlying neural, cognitive and behavioral processes [42]. Previous literature has suggested a relationship between pain and sleep [43], however, a paucity of multinational data exists on this topic. One could propose that back pain and sleep could also exist in a bidirectional relationship.

\subsection{Practical implications}

The current data have important public health implications, in particular since the data were multi-national, population-based, and predominantly nationally representative, rather than from clinical set- tings or the workplace. Understanding and treating comorbid pain and mental health outcomes are essential since both pain and mental health outcomes are worse than when any one stands in isolation $[44,45]$. An important environmental barrier in the care of people with mental and physical health problems in LMICs is however the lack of 
integrated mental and medical services and the poorly developed community- based psychiatric services [46]. Closer integration of primary and mental health care in these countries is needed, but without obscuring the responsibility for back pain and mental health assessment, prevention and management [47]. We suggest that back pain assessment, prevention and management in people with mental disorders should in the first place be the responsibility of the main mental health professional, while screening for mental health symptoms in people with a presentation of back pain should be the responsibility of the main treating physician or physiotherapist. However, it should be acknowledged that many professionals providing care for people with mental health conditions do not ask about back pain and many professionals providing care for people with back pain do not screen for symptoms of mental health conditions either because of a lack of consideration of this health care aspect, lack of time or lack of resources directly available to them [48]. Therefore, there is a clear need to ncrease awareness of the importance of physical health needs of people with mental disorders among mental health providers and mental health needs of LBP patients in physical health providers in LMICs. Clinicians should be aware that some people presenting with back pain may actually be presenting with 'masked depression' [49] and this may provide an opportunity for the treating physician to identify and offer appropriate treatment to such individuals. In our results we found evidence that lower education status is associated with higher back pain and such individuals may be more likely to conduct more manual work and experience back pain and also masked depression. In addition to pharmacological interven- tions, treatment and management modalities for LBP include behavior and exercise therapy and lifestyle change, many of which are relatively low-cost to implement in primary care settings [50]. Howev- er, most of what is known is based on studies executed in highincome settings [50]. Context-specific trials and evaluations in LMICs therefore are urgently needed.

\subsection{Study limitations and future research}

Some study design limitations need to be considered. First of all, the cross-sectional design precludes any certainty about the direction of the relationship between back pain and mental health disorders. Although cross-sectional studies cannot determine whether mental health symp- toms or disorders and back pain associations reflect causal links, a "dose-response" pattern with more back pain in mental disorders com- pared with milder mental health symptoms is at least consistent with a causal interpretation. It is important that future research attempts to understand the underlying explanatory factors of the relationships we observed. In addition, the questions from the CIDI used for the diagnosis of depression have been used extensively in international settings while the CIDI has been validated against clinical reappraisals [51]. However, convergent validity with the DSM-IV or DSM-V needs further assess- ment especially in LMICs. In addition, while our study assessed a num- ber of mental health conditions, future research may also wish to consider atypical depression, anxious depression and bipolarity symp- toms in relation to back pain. Another limitation is that the back pain questions were quite generic and future research may wish to consider more details regarding the history of symptoms and present back pain complains. Next, we were unable to conduct country-wise analyses as the sample size was too small in many of the countries. However, for the mental health outcomes for which region-wise analyses were possible, the associations with back pain were fairly consistent. Finally, we were unable to account for medication use in our analyses. Future research should therefore consider the impact of analgesic and psycho- tropic medication on the association between back pain and mental health outcomes. 
In conclusion, our data show that both back pain and chronic pain are associated with increased odds of depression, psychosis (including psychotic-like experiences), anxiety, stress, and sleep disturbances. Clearly, future research is required to determine the directionality of the relationships we observed and to inform the development of effective treatments.

Supplementary data to this article can be found online at http://dx. doi.org/10.1016/j.genhosppsych.2016.09.008.

\section{Conflict of interest}

All authors declare they have no conflict of interest.

\section{Acknowledgments}

BS receives funding from the National Institute for Health Research Collaboration for Leadership in Applied Health Research \& Care Funding scheme. The views expressed in this publication are those of the author(s) and not necessarily those of the NHS, the National Institute for Health Research or the Department of Health.

AK's work was supported by the Miguel Servet contract financed by the CP13/00150 and PI15/00862 projects, integrated into the National R + D + I and funded by the ISCIII General Branch Evaluation and Promotion of Health Research - and the European Regional Development Fund (ERDF-FEDER).

DV is funded by the Research Foundation Flanders (FWO - Vlaanderen).

\section{References}

[1] Hoy D, March L, Brooks P, Blyth F, Woolf A, Bain C, et al. The global burden of low back pain: estimates from the Global Burden of Disease 2010 study. Ann Rheum Dis 2014;73(6):968-74.

[2] Murray CJL, Vos T, Lozano R, Naghavi M, Flaxman AD, Michaud C, et al. Disabilityadjusted life years (DALYs) for 291 diseases and injuries in 21 regions, 1990-2010: a systematic analysis for the Global Burden of Disease Study 2010. Lan- cet 2012;380(9859):2197-223.

[3] FroudR,PattersonS,EldridgeS,SealeC,PincusT,RajendranD,etal.Asystematicre- view and meta-synthesis of the impact of low back pain on people's lives. BMC Musculoskelet Disord 2014;15:50.

[4] Dagenais S, Caro J, Haldeman S. A systematic review of low back pain cost of illness studies in the United States and internationally. Spine J 2008;8(1):8-20.

[5] Stanton TR, Latimer J, Maher CG, Hancock M. Definitions of recurrence of an episode of low back pain: a systematic review. Spine (Phila Pa 1976) 2009;34(9):E316-22. [6] Lambeek LC, van Tulder MW, Swinkels IC, Koppes LL, Anema JR, van Mechelen W.

The trend in total cost of back pain in The Netherlands in the period 2002 to 2007. 
Spine (Phila Pa 1976) 2011;36(13):1050-8. [7] Pinheiro MB, Ferreira ML, Refshauge K, Ordonana JR, Machado GC, Prado LR, et al.

Symptoms of depression and risk of new episodes of low back pain: a systematic re-

view and meta-analysis. Arthritis Care Res 2015;67(11):1591-603. [8] Pinheiro MB, Ferreira ML, Refshauge K, Maher CG, Ordonana JR, Andrade TB, et al. Symptoms of depression as a prognostic factor for low back pain: a systematic

review. Spine J 2016;16(1):105-16. [9]

JacksonT,ThomasS,StabileV,HanX,ShotwellM,McQueenK.Prevalenceofchronic

pain in low-income and middle-income countries: a systematic review and meta-

analysis. Lancet 2015;385(Suppl. 2):S10. [10] Stewart Williams J, Ng N, Peltzer K, Yawson A, Biritwum R, Maximova T, et al. Risk

factors and disability associated with low back pain in older adults in low- and middleincome countries. Results from the WHO Study on Global AGEing and Adult Health (SAGE). PLoS One 2015;10(6):e0127880.

[11] Demyttenaere K, Bruffaerts R, Lee S, Posada-Villa J, Kovess V, Angermeyer MC, et al. Mental disorders among persons with chronic back or neck pain: results from the World Mental Health Surveys. Pain 2007;129(3):332-42.

[12] Patel V, Araya R, Chatterjee S, Chisholm D, Cohen A, De Silva M, et al. Treatment and prevention of mental disorders in low-income and middle-income countries. Lancet 2007;370(9591):991-1005.

[13] Patel V, Chisholm D, Parikh R, Charlson FJ, Degenhardt L, Dua T, et al. Addressing the burden of mental, neurological, and substance use disorders: key messages from Disease Control Priorities, 3rd edition. Lancet 2016;387(10028):1672-85.

[14] Moussavi S, Chatterji S, Verdes E, Tandon A, Patel V, Ustun B. Depression, chronic diseases, and decrements in health: results from the World Health Surveys. Lancet 2007;370(9590):851-8.

[15] Kessler RC, Ustun TB. The World Mental Health (WMH) survey initiative version of the World Health Organization (WHO) Composite International Diagnostic Interview (CIDI). Int J Methods Psychiatr Res 2004;13(2):93-121.

[16] Ayuso-Mateos JL, Nuevo R, Verdes E, Naidoo N, Chatterji S. From depressive symptoms to depressive disorders: the relevance of thresholds. Br J Psychiatry J Ment Sci 2010;196(5):365-71.

[17] Cooper L, Peters L, Andrews G. Validity of the Composite International Diagnostic Interview (CIDI) psychosis module in a psychiatric setting. J Psychiatr Res 1998; 32(6):3618.

[18] Moreno C, Nuevo R, Chatterji S, Verdes E, Arango C, Ayuso-Mateos JL. Psychotic symptoms are associated with physical health problems independently of a mental disorder 
diagnosis: results from the WHO World Health Survey. World Psychiatry 2013;12(3):251-7.

[19] Koyanagi A, Stickley A. The association between psychosis and severe pain in community-dwelling adults: findings from 44 low- and middle-income countries. J Psychiatr Res 2015;69:19-26.

[20] StrangesS,TigbeW,Gomez-OliveFX,ThorogoodM,KandalaNB.Sleepproblems:an emerging global epidemic? Findings from the INDEPTH WHO-SAGE study among more than 40,000 older adults from 8 countries across Africa and Asia. Sleep 2012; 35(8):1173-81.

[21] KoyanagiA,GarinN,OlayaB,Ayuso-MateosJL,ChatterjiS,LeonardiM,etal.Chronic conditions and sleep problems among adults aged 50 years or over in nine countries: a multicountry study. PLoS One 2014;9(12), e114742.

[22] Koyanagi A, Stickley A. The association between sleep problems and psychotic symptoms in the general population: a global perspective. Sleep 2015;38(12): 1875-85.

[23] Wong KO, Hunter Rowe B, Douwes J, Senthilselvan A. Asthma and wheezing are associated with depression and anxiety in adults: an analysis from 54 countries. Pulm Med 2013;2013:929028.

[24] DeVylder JE, Koyanagi A, Unick J, Oh H, Nam B, Stickley A. Stress sensitivity and psychotic experiences in 39 low- and middle-income countries. Schizophr Bull 2016:sbw044.

[25] Koyanagi A, Stickley A, Garin N, Miret M, Ayuso-Mateos JL, Leonardi M, et al. The as- sociation between obesity and back pain in nine countries: a cross-sectional study. BMC Public Health 2015;15(1):123.

[26] Nuevo R, Chatterji S, Verdes E, Naidoo N, Arango C, Ayuso-Mateos JL. The continuum of psychotic symptoms in the general population: a cross-national study. Schizophr Bull 2012;38(3):475-85.

[27] Bair MJ, Robinson RL, Katon W, Kroenke K. Depression and pain comorbidity: a literature review. Arch Intern Med 2003;163(20):2433.

[28] Ossipov MH, Dussor GO, Porreca F. Central modulation of pain. J Clin Invest 2010; 120(11):3779-87.

[29] Millan MJ. Descending control of pain. Prog Neurobiol 2002;66(6):355-474.

[30] Saito T, Kai I, Takizawa A. Effects of a program to prevent social isolation on loneliness, depression, and subjective well-being of older adults: a randomized trial among older migrants in Japan. Arch Gerontol Geriatr 2012;55(3):539-47.

[31] Mammen G, Faulkner G. Physical activity and the prevention of depression: a systematic review of prospective studies. Am J Prev Med 2013;45(5):649-57.

[32] Klinedinst NJ, Resnick B, Yerges-Armstrong LM, Dorsey SG. The interplay of genetics, behavior, and pain with depressive symptoms in the elderly. Gerontologist 2015; 55(Suppl. 1):S67-77. 
[33] Deribew A, Tesfaye M, Hailmichael Y, Apers L, Abebe G, Duchateau L, et al. Common mental disorders in TB/HIV co-infected patients in Ethiopia. BMC Infect Dis 2010;10: 201.

[34] Kinyanda E, Kuteesa M, Scholten F, Mugisha J, Baisley K, Seeley J. Risk of major depressive disorder among older persons living in HIV-endemic central and south- western Uganda. AIDS Care 2016:1-6.

[35] Molony E, Westfall AO, Perry BA, Tucker R, Ritchie C, Saag M, et al. Low back pain and associated imaging findings among HIV-infected patients referred to an HIV/palliative care clinic. Pain Med 2014;15(3):418-24.

[36] Oh H, DeVylder J. Psychotic symptoms predict health outcomes even after adjusting for substance use, smoking and co-occurring psychiatric disorders: findings from the NCSR and NLAAS. World Psychiatry 2015;14(1):101-2.

[37] Koyanagi A, Stickley A, Haro JM. Subclinical psychosis and pain in an English national sample: the role of common mental disorders. Schizophr Res 2016.

[38] Stubbs B, Gardner-Sood P, Smith S, Ismail K, Greenwood K, Patel A, et al. Pain is independently associated with reduced health related quality of life in people with psychosis. Psychiatry Res 2015;230(2):585-91.

[39] Stubbs B, Thompson T, Acaster S, Vancampfort D, Gaughran F, Correll CU. Decreased pain sensitivity among people with schizophrenia: a meta-analysis of experimental pain induction studies. Pain 2015;156(11):2121-31.

[40] Saha S, Scott JG, Varghese D, McGrath JJ. The association between general psychological distress and delusional-like experiences: a large population-based study. Schizophr Res 2011;127(1-3):246-51.

[41] Asmundson GJ, Katz J. Understanding the co-occurrence of anxiety disorders and chronic pain: state-of-the-art. Depress Anxiety 2009;26(10):888-901.

[42] Vlaeyen JWS, Linton SJ. Fear-avoidance and its consequences in chronic musculoskeletal pain: a state of the art. Pain 2000;85(3):317-32.

[43] Alsaadi SM, McAuley JH, Hush JM, Maher CG. Prevalence of sleep disturbance in patients with low back pain. Eur Spine J 2011;20(5):737-43.

[44] Gerrits MM, Vogelzangs N, van Oppen P, van Marwijk HW, van der Horst H, Penninx BW. Impact of pain on the course of depressive and anxiety disorders. Pain 2012; 153(2):429-36.

[45] de Heer EW, Gerrits MM, Beekman AT, Dekker J, van Marwijk HW, de Waal MW, et al. The association of depression and anxiety with pain: a study from NESDA. PLoS One 2014;9(10), e106907.

[46] Weinmann S, Koesters M. Mental health service provision in low and middle- income countries: recent developments. Curr Opin Psychiatry 2016;29(4):270-5. 
[47] Petersen I, Evans-Lacko S, Semrau M, Barry MM, Chisholm D, Gronholm P, et al. Promotion, prevention and protection: interventions at the population- and community-levels for mental, neurological and substance use disorders in low- and middle-income countries. Int J Ment Heal Syst 2016;10:30.

[48] Eaton J, McCay L, Semrau M, Chatterjee S, Baingana F, Araya R, et al. Scale up of services for mental health in low-income and middle-income countries. Lancet 2011;378(9802):1592-603.

[49] Dworkin RH, Gitlin MJ. Clinical aspects of depression in chronic pain patients. Clin J Pain 1991;7(2):79-94.

[50] Lin CW, Haas M, Maher CG, Machado LA, van Tulder MW. Cost-effectiveness of general practice care for low back pain: a systematic review. Eur Spine J 2011;20(7): 101223.

[51] Haro JM, Arbabzadeh-Bouchez S, Brugha TS, de Girolamo G, Guyer ME, Jin R, et al. Concordance of the Composite International Diagnostic Interview Version 3.0 (CIDI 3.0) with standardized clinical assessments in the WHO World Mental Health surveys. Int J Methods Psychiatr Res 2006;15(4):167-80. 
Table 1 Age- and sex- adjusted prevalence of any back pain and chronic back pain by country

\begin{tabular}{|c|c|c|c|}
\hline Country & $\begin{array}{l}\text { Unweighted } \\
\mathrm{N}\end{array}$ & $\begin{array}{l}\text { Any back pain } \\
\%(\mathrm{SE})\end{array}$ & $\begin{array}{l}\text { Chronic back pain } \\
\% \text { (SE) }\end{array}$ \\
\hline "Burkina Faso & 4,948 & $29.5(1.4)$ & $4.1(0.6)$ \\
\hline Bangladesh & 5,942 & $53.1(1.0)$ & $10.9(0.8)$ \\
\hline Bosnia Herzegovina & 1,031 & $34.2(2.9)$ & $8.6(1.2)$ \\
\hline Brazil & 5,000 & $52.0(0.8)$ & $13.0(0.6)$ \\
\hline China & 3,994 & $13.7(1.0)$ & $2.6(0.4)$ \\
\hline Ivory Coast & 3,251 & 33.9 (1.6) & $5.9(0.8)$ \\
\hline Comoros & 1,836 & $32.4(1.8)$ & $3.2(0.5)$ \\
\hline Czech Republic & 949 & $47.5(2.6)$ & $13.3(1.6)$ \\
\hline $\begin{array}{l}\text { Dominican } \\
\text { Republic }\end{array}$ & 5,027 & $22.7(0.9)$ & $3.0(0.3)$ \\
\hline Ecuador & 5,675 & $28.9(1.4)$ & $4.3(0.7)$ \\
\hline Estonia & 1,020 & $37.6(2.1)$ & $8.6(1.0)$ \\
\hline Ethiopia & 5,089 & $25.3(1.1)$ & $4.1(0.4)$ \\
\hline Georgia & 2,950 & $20.2(1.3)$ & $3.3(0.5)$ \\
\hline Ghana & 4,165 & $21.9(0.9)$ & $4.6(0.4)$ \\
\hline Croatia & 993 & $49.3(2.2)$ & $12.9(1.4)$ \\
\hline Hungary & 1,419 & $40.0(1.7)$ & $12.7(0.8)$ \\
\hline India & 10,687 & $36.4(1.7)$ & $9.1(0.8)$ \\
\hline Kazakhstan & 4,499 & $33.8(1.3)$ & $4.1(0.5)$ \\
\hline Kenya & 4,640 & $27.1(1.1)$ & $5.1(0.6)$ \\
\hline Laos & 4,988 & $29.9(0.9)$ & $2.9(0.3)$ \\
\hline Sri Lanka & 6,805 & $23.7(1.1)$ & $3.2(0.4)$ \\
\hline Latvia & 929 & $45.6(2.4)$ & $11.0(1.3)$ \\
\hline Morocco & 5,000 & $45.8(1.3)$ & $16.5(1.0)$ \\
\hline Myanmar & 6,045 & $18.7(1.2)$ & $0.6(0.1)$ \\
\hline Mauritania & 3,902 & $33.2(1.4)$ & $1.7(0.4)$ \\
\hline Mauritius & 3,968 & $27.5(1.4)$ & $5.0(0.6)$ \\
\hline Malawi & 5,551 & $30.4(1.1)$ & $3.5(0.5)$ \\
\hline Malaysia & 6,145 & $23.5(0.8)$ & $1.8(0.2)$ \\
\hline Namibia & 4,379 & $26.1(1.0)$ & $4.3(0.6)$ \\
\hline Nepal & 8,820 & $57.1(0.7)$ & $16.4(0.6)$ \\
\hline Pakistan & 6,501 & $26.3(0.8)$ & $7.3(0.5)$ \\
\hline Philippines & 10,083 & $41.9(1.1)$ & $1.8(0.2)$ \\
\hline Paraguay & 5,288 & $37.2(0.9)$ & $5.8(0.4)$ \\
\hline Russia & 4,427 & $41.1(2.1)$ & $6.7(0.9)$ \\
\hline Senegal & 3,461 & $26.8(1.3)$ & $3.9(0.6)$ \\
\hline Chad & 4,870 & $44.8(1.6)$ & $8.7(0.8)$ \\
\hline Tunisia & 5,202 & $29.1(1.0)$ & $5.9(0.5)$ \\
\hline Ukraine & 2,860 & $44.2(1.8)$ & $10.9(0.9)$ \\
\hline Uruguay & 2,996 & $23.8(1.2)$ & $3.9(0.4)$ \\
\hline Vietnam & 4,174 & 28.3 (1.9) & $3.0(0.6)$ \\
\hline South Africa & 2,629 & $30.3(1.4)$ & $2.5(0.5)$ \\
\hline Zambia & 4,165 & $25.6(1.0)$ & $2.3(0.3)$ \\
\hline Zimbabwe & 4,290 & $28.1(1.1)$ & $3.4(0.5)$ \\
\hline
\end{tabular}

Abbreviation: SE standard error

All age- and sex-adjusted weighted estimates were calculated using the United Nations population pyramids for the year 2010. 
Table 2 Sample characteristics (overall and by any back pain or chronic back pain)

\begin{tabular}{|c|c|c|c|c|c|c|c|}
\hline \multirow[b]{2}{*}{ Characteristics } & \multirow[b]{2}{*}{ Overall } & \multicolumn{3}{|c|}{ Any back pain } & \multicolumn{3}{|c|}{ Chronic back pain } \\
\hline & & No & Yes & $\mathrm{P}$-value & No & Yes & P-value \\
\hline Age (years) Mean (SD) & $\begin{array}{l}38.4 \\
(16.0)\end{array}$ & $\begin{array}{l}35.9 \\
(15.3)\end{array}$ & $\begin{array}{l}43.1 \\
(16.2)\end{array}$ & $\begin{array}{l}<0.000 \\
1\end{array}$ & $\begin{array}{l}37.5 \\
(15.7)\end{array}$ & $\begin{array}{l}48.7 \\
(15.8)\end{array}$ & $\begin{array}{l}<0.000 \\
1\end{array}$ \\
\hline Sex & & & & & & & \\
\hline Male & 49.3 & 53.9 & 40.9 & $\begin{array}{l}<0.000 \\
1\end{array}$ & 50.6 & 33.4 & $\begin{array}{l}<0.000 \\
1\end{array}$ \\
\hline $\begin{array}{l}\text { Female } \\
\text { Education }\end{array}$ & 50.7 & 46.1 & 59.1 & & 49.4 & 66.6 & \\
\hline No formal & 28.0 & 25.5 & 31.9 & $\begin{array}{l}<0.000 \\
1\end{array}$ & 26.7 & 41.7 & $\begin{array}{l}<0.000 \\
1\end{array}$ \\
\hline$\leq$ Primary & 32.3 & 31.9 & 33.2 & & 32.6 & 30.1 & \\
\hline Secondary completed & 29.8 & 31.8 & 26.6 & & 30.5 & 21.9 & \\
\hline $\begin{array}{l}\text { Tertiary completed } \\
\text { Wealth }\end{array}$ & 9.8 & 10.7 & 8.3 & & 10.1 & 6.3 & \\
\hline Poorest & 20.1 & 19.1 & 22.2 & $\begin{array}{l}<0.000 \\
1\end{array}$ & 19.9 & 23.9 & $\begin{array}{l}<0.000 \\
1\end{array}$ \\
\hline Poorer & 20.0 & 19.1 & 21.3 & & 19.7 & 22.0 & \\
\hline Middle & 19.9 & 19.8 & 20.2 & & 19.9 & 20.3 & \\
\hline Richer & 20.0 & 20.4 & 19.2 & & 20.2 & 17.3 & \\
\hline Richest & 20.0 & 21.7 & 17.1 & & 20.3 & 16.5 & \\
\hline Setting & & & & & & & \\
\hline Rural & 58.8 & 59.6 & 56.9 & 0.0002 & 58.9 & 56.8 & 0.0969 \\
\hline Urban & 41.2 & 40.4 & 43.1 & & 41.1 & 43.2 & \\
\hline $\begin{array}{l}\text { Current smoking } \\
\text { Alcohol consumption }\end{array}$ & 26.7 & 24.8 & 30.1 & & 26.4 & 30.6 & \\
\hline Lifetime abstainer & 67.4 & 70.3 & 61.8 & $\begin{array}{l}<0.000 \\
1\end{array}$ & 67.7 & 63.0 & $\begin{array}{l}<0.000 \\
1\end{array}$ \\
\hline Non-heavy & 27.6 & 24.9 & 33.0 & & 27.2 & 33.9 & \\
\hline Infrequent heavy & 3.8 & 3.7 & 4.0 & & 3.9 & 2.3 & \\
\hline $\begin{array}{l}\text { Frequent heavy } \\
\text { Depression type }\end{array}$ & 1.1 & 1.1 & 1.2 & & 1.1 & 0.8 & \\
\hline No depression & 87.8 & 92.5 & 77.6 & $\begin{array}{l}<0.000 \\
1\end{array}$ & 89.1 & 64.4 & $\begin{array}{l}<0.000 \\
1\end{array}$ \\
\hline Subsyndromal depression & 2.5 & 1.8 & 4.1 & & 2.3 & 7.1 & \\
\hline Brief depressive episode & 2.9 & 1.8 & 5.2 & & 2.7 & 6.0 & \\
\hline $\begin{array}{l}\text { Depressive episode } \\
\text { Psychosis }\end{array}$ & 6.8 & 3.9 & 13.1 & & 5.9 & 22.5 & \\
\hline Symptom (-) Diagnosis (-) & 84.7 & 88.8 & 76.9 & $\begin{array}{l}<0.000 \\
1\end{array}$ & 85.5 & 72.8 & $\begin{array}{l}<0.000 \\
1\end{array}$ \\
\hline Symptom (+) Diagnosis (-) & 14.2 & 10.4 & 21.4 & & 13.5 & 24.8 & \\
\hline Symptom (-) Diagnosis (+) & 0.5 & 0.3 & 0.8 & & 0.5 & 0.8 & \\
\hline Symptom $(+)$ Diagnosis $(+)$ & 0.6 & 0.4 & 0.9 & & 0.5 & 1.7 & \\
\hline Anxiety $^{a}$ & 12.0 & 8.2 & 19.2 & $\begin{array}{l}<0.000 \\
1\end{array}$ & 10.8 & 29.3 & $\begin{array}{l}<0.000 \\
1\end{array}$ \\
\hline Sleep problems & 8.0 & 4.3 & 14.9 & $\begin{array}{l}<0.000 \\
1\end{array}$ & 6.8 & 24.3 & $\begin{array}{l}<0.000 \\
1\end{array}$ \\
\hline $\begin{array}{l}\text { Stress sensitivity }{ }^{\mathbf{b}} \text { Mean } \\
\text { (SD) }\end{array}$ & $4.9(2.2)$ & $4.7(2.2)$ & $5.5(2.2)$ & $\begin{array}{l}<0.000 \\
1\end{array}$ & $4.9(2.2)$ & $5.9(2.2)$ & $\begin{array}{l}<0.000 \\
1\end{array}$ \\
\hline
\end{tabular}

Abbreviation: SD standard deviation

Data are weighted column (\%) unless otherwise stated.

${ }^{a}$ Morocco is not included.

${ }^{b}$ Brazil, Hungary, and Zimbabwe are not included. The stress sensitivity score ranges from 2-10 with higher scores indicating higher levels of stress sensitivity. 
(c) 2016. This manuscript version is made available under the CC-BY-NC-ND 4.0 license http://creativecommons.org/licenses/by-nc-nd/4.0/

Table 3 The association between mental health conditions and (a) any back pain or (b) chronic back pain (overall and by sex) estimated by multivariable logistic regression

\begin{tabular}{|c|c|c|c|c|c|c|c|}
\hline \multirow{2}{*}{ (a) Any back pain } & & \multicolumn{2}{|l|}{ Overall } & \multicolumn{2}{|l|}{ Female } & \multicolumn{2}{|l|}{ Male } \\
\hline & & $\mathrm{OR}$ & $95 \% \mathrm{CI}$ & OR & $95 \% \mathrm{CI}$ & OR & $95 \% \mathrm{CI}$ \\
\hline \multirow[t]{4}{*}{ Depression type } & No depression & 1.00 & & 1.00 & & 1.00 & \\
\hline & Subsyndromal depression & $2.21^{* *}$ & {$[1.91,2.54]$} & $2.08^{* *}$ & {$[1.77,2.44]$} & $2.37 * *$ & {$[1.85,3.02]$} \\
\hline & Brief depressive episode & $2.64^{* *}$ & {$[2.33,2.99]$} & $2.42 * *$ & {$[2.07,2.81]$} & $3.03^{* *}$ & {$[2.49,3.70]$} \\
\hline & Depressive episode & $2.88 * *$ & {$[2.63,3.17]$} & $2.53 * *$ & {$[2.25,2.84]$} & $3.48 * *$ & {$[2.94,4.12]$} \\
\hline \multirow[t]{4}{*}{ Psychosis } & Symptom (-) Diagnosis (-) & 1.00 & & 1.00 & & 1.00 & \\
\hline & Symptom (+) Diagnosis (-) & $2.01^{* *}$ & {$[1.88,2.16]$} & $2.04^{* *}$ & {$[1.86,2.23]$} & $2.01^{* *}$ & {$[1.81,2.23]$} \\
\hline & Symptom (-) Diagnosis (+) & $2.51^{* *}$ & {$[1.87,3.39]$} & $2.71 * *$ & {$[1.78,4.13]$} & $2.33^{* *}$ & {$[1.48,3.65]$} \\
\hline & Symptom $(+)$ Diagnosis $(+)$ & $2.05 * *$ & {$[1.64,2.57]$} & $1.83^{* *}$ & {$[1.32,2.53]$} & $2.38 * *$ & {$[1.74,3.25]$} \\
\hline Anxiety $^{\mathrm{a}}$ & Yes vs. No & $2.12 * *$ & {$[1.96,2.29]$} & $1.98 * *$ & {$[1.80,2.18]$} & $2.31^{* *}$ & {$[2.05,2.61]$} \\
\hline Sleep problems & Yes vs. No & $2.37 * *$ & {$[2.19,2.57]$} & $2.30 * *$ & {$[2.08,2.54]$} & $2.46^{* *}$ & {$[2.16,2.81]$} \\
\hline Stress sensitivity ${ }^{\mathrm{b}}$ & (per unit increase) & $1.13^{* *}$ & {$[1.12,1.15]$} & $1.13^{* *}$ & {$[1.11,1.15]$} & $1.13^{* *}$ & {$[1.11,1.16]$} \\
\hline & & Overall & & Female & & Male & \\
\hline \multicolumn{2}{|c|}{ (b) Chronic back pain } & OR & $95 \% \mathrm{CI}$ & OR & $95 \% \mathrm{CI}$ & OR & $95 \% \mathrm{CI}$ \\
\hline \multirow[t]{4}{*}{ Depression type } & "No depression & 1.00 & & 1.00 & & 1.00 & \\
\hline & Subsyndromal depression & $2.89 * *$ & {$[2.36,3.56]$} & $2.65^{* *}$ & {$[2.11,3.33]$} & $3.36 * *$ & {$[2.24,5.03]$} \\
\hline & Brief depressive episode & $2.06^{* *}$ & {$[1.73,2.46]$} & $2.00 * *$ & {$[1.63,2.46]$} & $2.10^{* *}$ & {$[1.46,3.03]$} \\
\hline & Depressive episode & $3.12^{* *}$ & {$[2.76,3.52]$} & $2.77 * *$ & {$[2.40,3.21]$} & $3.92 * *$ & {$[3.23,4.76]$} \\
\hline \multirow[t]{4}{*}{ Psychosis } & Symptom (-) Diagnosis (-) & 1.00 & & 1.00 & & 1.00 & \\
\hline & Symptom (+) Diagnosis (-) & $1.72 *$ & {$[1.54,1.92]$} & $1.69 * *$ & {$[1.48,1.92]$} & $1.78 * *$ & {$[1.47,2.15]$} \\
\hline & Symptom (-) Diagnosis (+) & $1.62 *$ & {$[1.08,2.43]$} & $1.69 *$ & {$[1.02,2.82]$} & 1.50 & {$[0.79,2.86]$} \\
\hline & Symptom $(+)$ Diagnosis $(+)$ & $2.68 * *$ & {$[1.93,3.73]$} & $2.23^{* *}$ & {$[1.49,3.34]$} & $3.51^{* *}$ & {$[2.10,5.88]$} \\
\hline Anxiety ${ }^{a}$ & Yes vs. No & $2.45^{* *}$ & {$[2.19,2.74]$} & $2.35^{* *}$ & {$[2.07,2.67]$} & $2.61^{* *}$ & {$[2.12,3.21]$} \\
\hline Sleep problems & Yes vs. No & $2.38 * *$ & {$[2.13,2.65]$} & $2.14 * *$ & {$[1.88,2.44]$} & $2.99 * *$ & {$[2.47,3.61]$} \\
\hline Stress sensitivity ${ }^{\mathrm{b}}$ & (per unit increase) & $1.15^{* *}$ & {$[1.13,1.18]$} & $1.14^{* *}$ & {$[1.11,1.17]$} & $1.18^{* *}$ & {$[1.13,1.23]$} \\
\hline
\end{tabular}

Abbreviation: OR odds ratio; CI confidence interval

The mental health conditions were included separately in the models.All models are adjusted for age, education, wealth, setting (rural or urban), smoking, alcohol consumption, and country. The model using the overall sample also adjusted for sex.

Significant interaction by sex(in bold font) for depressive episode (back pain and chronic back pain) and sleep problems (chronic back pain).

${ }^{\mathrm{a}}$ Morocco is not included.

bBrazil, Hungary, and Zimbabwe are not included. The stress sensitivity score ranges from 2-10 with higher scores indicating higher levels of stress sensitivity.

${ }^{*} \mathrm{p}<0.05,{ }^{* *} \mathrm{p}<0.001$ 
(c) 2016. This manuscript version is made available under the CC-BY-NC-ND 4.0 license http://creativecommons.org/licenses/by-nc-nd/4.0/

(a) Any back pain

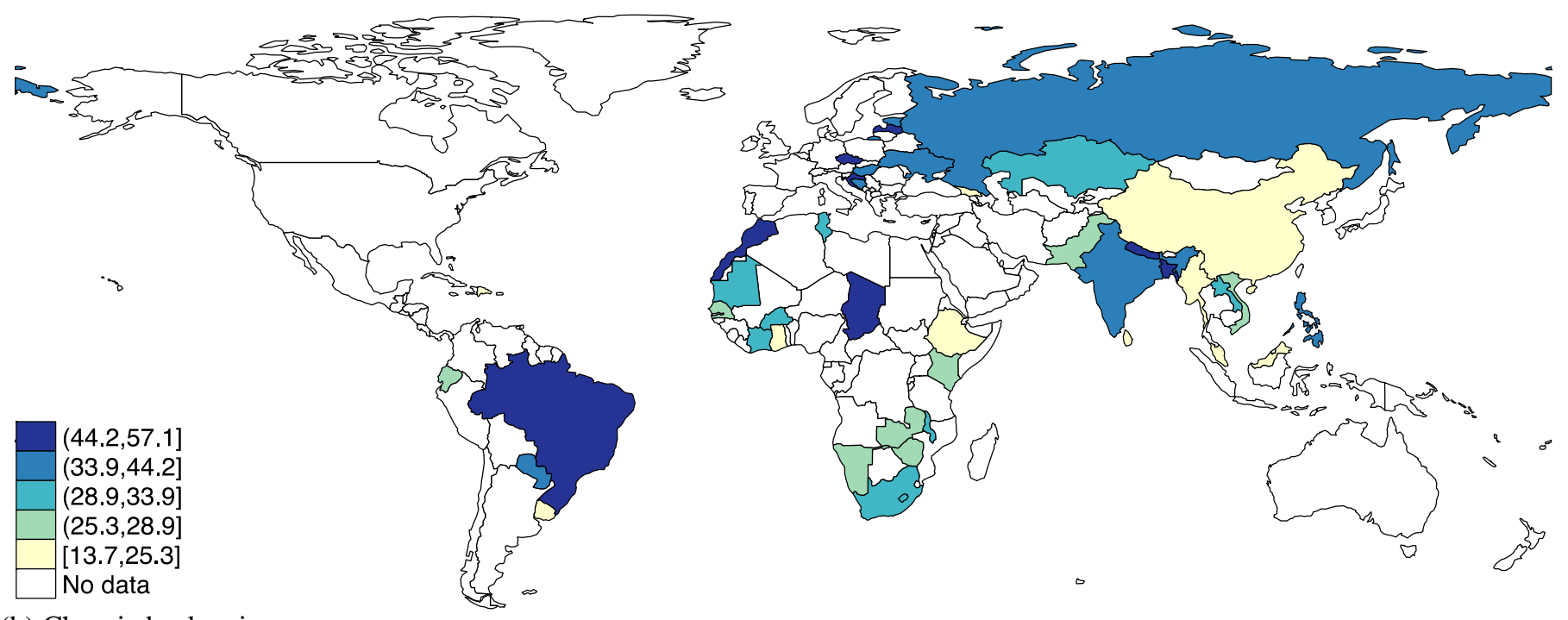

(b) Chronic back pain

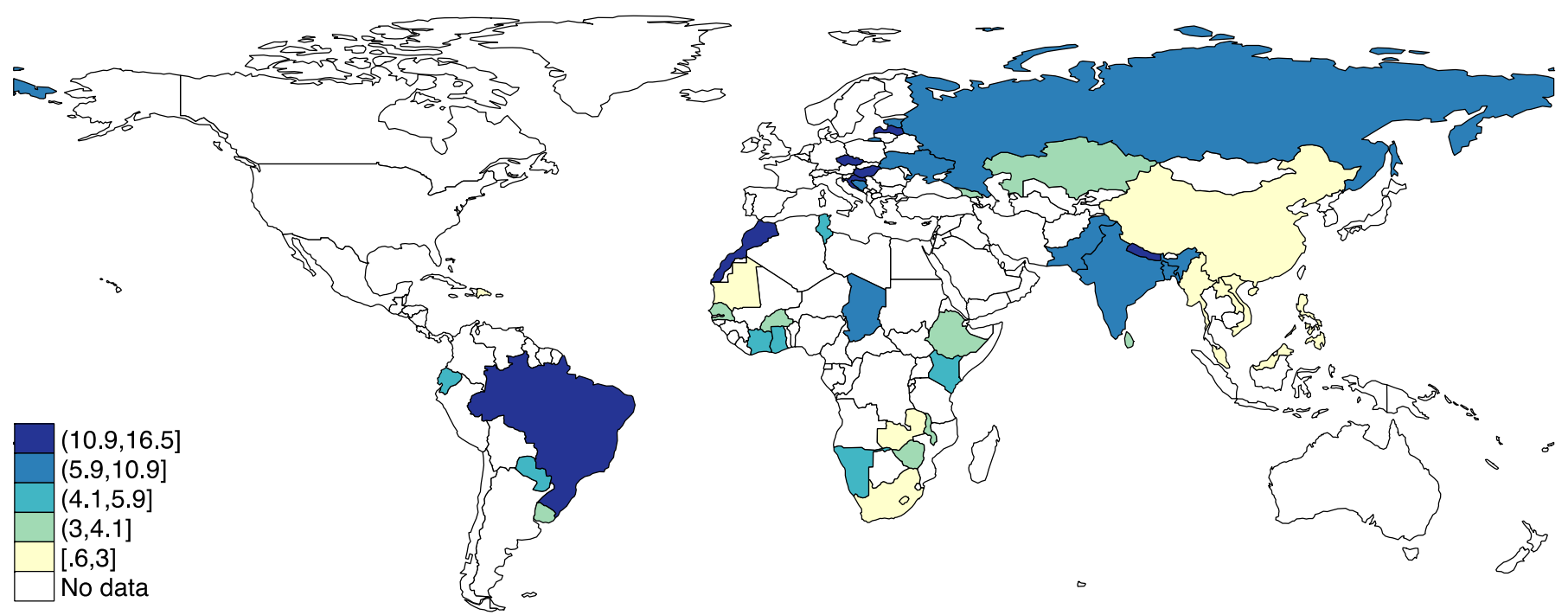

Figure 1The age- and sex-adjusted prevalence of (a) any back pain and (b) chronic back pain

All age- and sex-adjusted weighted estimates were calculated using the United Nations population pyramids for the year 2010. 




Figure 2 Prevalence of any back pain and chronic back pain by mental health conditions

Estimates are based on weighted sample. Bars denote 95\% confidence intervals. 